\title{
Protagonismo juvenil: a percepção de jovens sobre o tema das sexualidades na escola
}

Thiago de Souza Moura ${ }^{1}$

\begin{abstract}
Resumo:
A juventude percebe a escola como um espaço de silêncio ou um lugar aberto para diálogos? O presente estudo apresenta reflexões sobre a ausência ou presença do protagonismo juvenil, referente ao tema da sexualidade no âmbito escolar. A questão principal da pesquisa é: os jovens, de fato, possuem espaço para serem protagonistas das discussões sobre sexualidade na escola? Ao longo deste trabalho, foram analisadas as percepções dos jovens sobre o exercício do protagonismo juvenil, na construção de suas sexualidades no ambiente escolar. Para tal, participaram do estudo, quatorze estudantes dos anos finais do ensino fundamental, com faixa etária entre quatorze e dezessete anos de idade, em uma escola pública no interior do Rio de Janeiro. A metodologia qualitativa encontra-se empregada neste estudo através de oficinas pedagógicas. O referencial teórico norteador deste trabalho, se apoia em uma tentativa de aprofundamento das questões sociológicas da sexualidade na escola em contrapartida aos discursos biológicos, que regem o tema. Entre as percepções dos estudantes, percebe-se uma escassez de diálogos acerca da sexualidade, deixando em segundo plano considerações sobre suas subjetividades. A figura do professor entra em voga como um fator determinante ou não, para que o tema da sexualidade seja abordado na escola.
\end{abstract}

\section{Palavras-chave:}

Juventudes. Protagonismo juvenil. Sexualidade. Escola. Educação.

\section{Youth protagonism: the perception of young people on the topic of sexualities at school}

\begin{abstract}
Do youth perceive school as a space of silence or an open place for dialogues? This study presents reflections on the absence or presence of youth protagonism, referring to the theme of sexuality in the school environment. The main question of the research is: do young people, in fact, have space to be protagonists of discussions about sexuality at school? Throughout this work, young people's perceptions about the exercise of youth protagonism in the construction of their sexualities in the school environment were analyzed. To this end, fourteen students from the final years of elementary school, aged between
\end{abstract}

1 Mestre em Educação. E-mail: benjaminocita@gmail.com. ORCID iD: http://orcid.org/0000-0003-1590-5745.

2 Mestra em Ciências Humanas. E-mail: marinapuc-rio@hotmail.com. ORCID iD: http://orcid.org/0000-0002-3581-0922. 
fourteen and seventeen years old, participated in the study, in a public school in the interior of Rio de Janeiro. The qualitative methodology is used in this study through pedagogical workshops. The theoretical framework guiding this work is based on an attempt to deepen the sociological issues of sexuality at school, in contrast to the biological discourses that govern the theme. Among the students' perceptions, there is a scarcity of dialogues about sexuality, and considerations about their subjectivities are left in the background. The figure of the teacher comes into vogue as a determining factor or not, so that the topic of sexuality is addressed at school.

Keywords: Youths. Youth protagonism. Sexualities. School. Education.

\section{Protagonismo juvenil: la percepción de los jóvenes sobre el tema de las sexualidades en la escuela}

Resumen: Los jóvenes perciben la escuela como un espacio de silencio o un lugar abierto para el diálogo? Este estudio presenta reflexiones sobre la ausencia o presencia del protagonismo juvenil, refiriéndose al tema de la sexualidad en el ámbito escolar. La pregunta principal de la investigación es: los jóvenes, de hecho, ¿tienen espacio para ser protagonistas de discusiones sobre sexualidad en la escuela? A lo largo de este trabajo se analizaron las percepciones de los jóvenes sobre el ejercicio del protagonismo juvenil en la construcción de sus sexualidades en el ámbito escolar. Para ello, participaron catorce estudiantes de los últimos años de la escuela primaria, con edades comprendidas entre los catorce y los diecisiete años, en una escuela pública del interior de Río de Janeiro. La metodología cualitativa se utiliza en este estudio a través de talleres pedagógicos. El marco teórico que guía este trabajo se basa en un intento de profundizar en la problemática sociológica de la sexualidad en la escuela, en contraposición a los discursos biológicos que rigen la temática. Entre las percepciones de los estudiantes, hay escasez de diálogos sobre la sexualidad y las consideraciones sobre sus subjetividades quedan en un segundo plano. La figura del docente se pone de moda como factor determinante o no, por lo que el tema de la sexualidad se aborda en la escuela.

Palabras clave: Jóvenes. Protagonismo juvenil. Sexualidades. Colegio. Educación.

\section{Introdução}

O ambiente escolar apresenta-nos um mundo de possibilidades de reflexões, afinal, neste lugar, podemos acompanhar os processos de formação dos sujeitos ao longo do ano letivo. Tal realidade abre diversas oportunidades de campo investigativo no âmbito das pesquisas educacionais. Para este estudo, foram realizadas análises das percepções dos jovens sobre como é tratado o tema da sexualidade no cotidiano escolar, a partir da seguinte questão norteadora: os jovens, de fato, possuem espaço para serem protagonistas das discussões sobre sexualidade na escola?

No ano de 2020 houve o pronunciamento ${ }^{1}$ da Ministra Damares Alves, representante do Ministério da Mulher, Família e Direitos Humanos (MDH), a respeito do tema "educação sexual". A então ministra apresentou o uso da abstinência sexual como "método preventivo educacional" para utilização dos jovens. Diante desse contexto político, cabe refletir sobre as seguintes questões: esse posicionamento originou-se segundo quais princípios? Os jovens em questão foram ouvidos para debaterem essa proposta? Esse debate alcançou as escolas, seus alunos e professores? Quais dados científicos podem corroborar tais afirmações em uma política pública viável, que atenda ao público jovem? Como ocorre a discussão sobre sexualidade nas escolas?

1 Reportagem sobre Abstinência Sexual como proposta para Educação Sexual. Disponível em: https://www.correio24horas.com.br/ noticia/nid/damares-aposta-em-abstinencia-sexual-para-evitar-gravidez-precoce/. Acesso em: 15 jan. 2020. 
O que se sabe é que, frequentemente, a educação sexual é abordada sendo associada às questões biológicas, sem uma análise e reflexão das subjetividades dos sujeitos envolvidos no processo e o protagonismo juvenil nesses debates (ALTMAN, 2001, 2005). As características biológicas e higienistas na educação sexual têm ligação ao processo de formação histórica do tema relacionado à área de saúde. Portanto, considerações de caráter sociológico voltadas para o estudo das subjetividades dos sujeitos em relação ao processo de construção de suas sexualidades se torna um processo preterido na sociedade, sobretudo, na escola (CÉSAR, 2009).

Diante disso, esta pesquisa apresenta como objetivo central, a identificação das percepções dos estudantes dos anos finais do ensino fundamental sobre o tema da sexualidade na escola, amparado pelo arcabouço teórico-metodológico dos estudos sociológicos para análise do assunto no ambiente escolar. O trabalho foi desenvolvido em uma escola pública no interior do Estado do Rio de Janeiro com a participação de catorze estudantes (doze meninas e dois meninos) dos anos finais do ensino fundamental, com idade entre quatorze e dezessete anos.

A pesquisa qualitativa amparou o desenvolvimento do estudo, pois se configura em um caminho direcionado para o reconhecimento do: "universo de significados, motivos, aspirações, crenças, valores e atitudes que permeiam a subjetividade dos sujeitos" (MINAYO, 2007, p. 21). Como instrumento metodológico, foram realizadas oficinas pedagógicas.

O processo de construção das oficinas pedagógicas ocorreu no ano de 2018 em dois encontros no contraturno escolar. No primeiro dia, os jovens tiveram contato com o documentário Meninas ${ }^{2}$ que aborda considerações sobre a gravidez na adolescência. Assim, dentro da esfera de debates e reflexões lidaram com discussões sobre os estigmas (preconceito, abandono escolar, conflitos familiares, insuficiência de maturidade, pai adolescente não se envolve no processo e pobreza) e contrapontos (amadurecimento, desejo como projeto de vida, liberdade, prazer e aproximação dos jovens com a família) da gravidez adolescente a partir de suas percepções acerca do tema trazido à tona pelo documentário. No segundo dia, os jovens tiveram contato com casos reais de gravidez na adolescência através de matérias de jornais e sites. E discutiram alguns jargões associados ao "ser-mulher e ao ser-homem" na sociedade. Em ambos os dias, cada discussão teve respaldo nos estudos de gênero sobre as relações sociais. A gravidez na adolescência, um dos eixos da educação sexual, foi usada como um dos veículos para aprofundamento da sexualidade na escola. Segue no corpo do artigo considerações em relação ao estudo do protagonismo juvenil no tema da sexualidade na escola associado aos achados do campo estudado.

\section{A sexualidade negligenciada no cotidiano escolar}

A escola ainda se dedica ao ensino dos conteúdos legitimados por grupos, que privilegiam posições que desclassificam as diferenças nos domínios de marcadores sociais, como aqueles das sexualidades. Nesse contexto, o conjunto de temas que envolve as sexualidades sofre com a invisibilidade. Segundo Rocha (2013), a escola silencia em suas ações e apaga de seus discursos todas as possibilidades de gênero e sexualidades, que não sejam legitimadas pela heterossexualidade reprodutiva. Diante disso, embora a diversidade de sexualidades esteja presente nas escolas, a vivência dos estudantes pode perpassar nesse lugar por momentos de silenciamento e exclusão, caso não estejam de acordo com a heteronormatividade imposta.

Rocha (2013) afirma que durante os seus 12 anos de experiência no magistério na rede pública, a prática mais comum foi o silenciamento e até punições para aqueles que insistiam em exercer de outras maneiras a sua sexualidade, conforme o relato.

Na mesma entrevista de 26 de março de 2012, as alunas relataram situações de punição a alunos(as) que encenaram performances homoafetivas dentro da escola, comparando os casos a situações idênticas nas quais performances heteroafetivas não receberam punição. (p. 17).

2 Documentário: Meninas. Disponível em: https://www.youtube.com/watch?v=bXbToN1ILPY. Acesso em: 15 ago. 2018. 
A escolarização tradicional que negligencia a temática provoca o silenciamento nocivo, causa sofrimento e limita a experiência dos jovens em viver e (re)conhecer a multiplicidade de possibilidades de gêneros e sexualidades, presentes na nossa sociedade. Desse modo, desde a seleção de conhecimentos até às metodologias adotadas, a escola ensina quais modos de vida humana são mais legítimos.

As sexualidades dos alunos têm se apresentado a partir de seus próprios posicionamentos-protagonismos na escola, em contrapartida à ausência de abordagens acerca do assunto neste lugar. O autor Bortolini (2008) nos apresenta reflexões sobre essa realidade em seu trabalho:

Se antes esses(as) estudantes eram simplesmente invisíveis, se passavam toda a sua trajetória escolar dentro de 'armários' (mesmo que de vidro), hoje esses(as) jovens estão assumindo identidades e enfrentando a escola, professores(as), diretores(as) e colegas pelos seus direitos. (p. 31).

Esse cenário de silenciamento para o tema das sexualidades, nos faz refletir sobre a importância da revisão de práticas escolares que estejam voltadas para o reconhecimento do multiculturalismo e da inclusão da diversidade. Para tanto, dialogamos com o "protagonismo juvenil", que além de valorizar a voz dos nossos estudantes, reconhece a diversidade como uma potência e não como um problema a ser combatido.

Assim, defendemos neste estudo que o tema "educação sexual" seja tratado nas escolas, de maneira articulada aos conhecimentos biológicos e às questões culturais, visando a construção de um currículo para vida (KINDEL, 2012) e que a sexualidades e volte para o estudo das subjetividades dos sujeitos em sua diversidade.

\section{O protagonismo juvenil}

O termo "protagonismo juvenil" não é recente no campo da educação. Propõe-se que o jovem participe ativamente de todo o processo da ação educativa, que tem início na escola, mas não se restringe a ela. O protagonismo juvenil prioriza a formação de jovens autônomos e legitima a sua participação social.

Dayrell (2003) define a juventude como parte de um processo mais amplo de constituição dos sujeitos, a partir das particularidades que cercam a vida de cada um. Para o autor, é fundamental que o jovem seja compreendido como sujeito social, que constrói "modos" de ser jovem, de acordo com as suas experiências cotidianas. Nessa perspectiva, é reconhecida a diversidade juvenil, concretizada através das condições sociais, culturais, de gênero, regionais, dentre outras especificidades. Cabe refletir como o meio social, nesse caso, a escola, promove o desenvolvimento das potencialidades dos jovens, garantindo-lhes um espaço de protagonismo, ou seja, um papel propriamente ativo na sociedade.

Souza (2009) buscou sintetizar alguns resultados da pesquisa realizada em textos diversos (artigos, livros, textos publicados nos sites da internet, legislação, matérias de jornais e revistas, relatórios de conferências e congressos) produzidos entre os anos de 1985 e 2005, "por organizações não-governamentais (ONGs), órgãos de governo, organismos internacionais e pesquisadores acadêmicos" (p. 2), que trataram sobre a temática da participação da juventude.

Com a pesquisa realizada foi possível identificar e delimitar determinado discurso sobre a juventude produzido a partir de meados dos anos 80 . Posteriormente esse discurso foi reunido e consolidado diante da emergência do enunciado "protagonismo juvenil". Assim, o principal objetivo de Souza (2009) foi identificar nos escritos (ou em fragmentos dos escritos), a maior ou menor presença de determinado discurso, que mesmo não sendo único, tendo em vista que os discursos são por vezes distintos e contraditórios, mostrou-se predominante. Deste modo, o "protagonismo juvenil" consiste no conjunto de ideias, argumentos e orientações para ação; trata-se do discurso sobre a participação da juventude na sociedade. 
No final da década de 70, houve um dos primeiros marcos desse discurso: as Organizações das Nações Unidas declararam o ano de 1985 como o Ano Internacional da Juventude: Participação, Desenvolvimento e Paz. Desde então, foram desenvolvidas políticas públicas de juventude que prescrevem uma forma determinada de participação dos jovens nessas políticas. Assim, determinados órgãos das Nações Unidas produziram documentos, resultantes de fóruns, seminários e outros encontros, nos quais programas de ação, diretrizes e medidas foram estabelecidas pelos países-membros, formando o campo das políticas públicas de juventude.

Os organismos internacionais (ONU, Unesco, Cepal etc.) recomendavam políticas públicas voltadas, principalmente, aos segmentos da juventude em situação de vulnerabilidade social pobreza, exclusão, desemprego, violência, delinquência, drogas, HIV/AIDS, gravidez não-prevista (HEIBORN, 2006), entre outros. Nesse sentido, o objetivo das propostas era permitir aos jovens o acesso ao incentivo do empreendedorismo juvenil e à construção de uma cultura de paz. Diante disso, é possível identificar que a preocupação principal das agências internacionais e dos governos eram os riscos de desestabilização social, consequência da situação de pobreza e exclusão de uma parcela considerável da população juvenil.

Aos poucos o Brasil passou a adotar as recomendações internacionais. Souza (2009) reconhece que o discurso do "protagonismo juvenil" embasou as políticas da educação brasileira, no entanto, esclarece que esse discurso não parte dos jovens e sim dos adultos. Ou seja, não é o jovem que detém o poder de decisão e deliberação sobre suas ações. Trata-se, portanto, de um discurso que prescreve (ou impõe) determinado modelo de "participação" juvenil que tenta se mostrar transformador, mas na verdade é apenas integrador. Os jovens são integrados ao coletivo adulto, sem que as suas subjetividades sejam reconhecidas. Nesse sentido, as desigualdades estruturais e as contradições sociais são omitidas, o indivíduo - "ator social" - é o único responsável por seus êxitos ou fracassos, uma vez que as posições de classe e condições históricas, econômicas e sociais não são consideradas.

Dessa forma, é utilizado um determinado modelo de "participação" para defesa dos interesses, mas na realidade o que ocorre é a reafirmação de questões previamente definidas por outras instâncias, sem a efetiva participação dos jovens. Já que os rumos dos acontecimentos não são alterados, a "atuação social" do jovem consiste basicamente em trabalho não remunerado, apresentado como um meio de transformação social. Assim, para Souza (2009), o discurso do "protagonismo juvenil" é apenas uma encenação, que não garante o poder de decisão, criação e nem mudança de rumos dos acontecimentos. Consiste, sim, em um discurso hegemônico, autoritário e manipulador, distante de ações autônomas e conscientes de participação coletiva.

Para que o protagonismo juvenil seja efetivamente garantido cabe que as subjetividades dos jovens sejam reconhecidas e norteadoras das ações educativas. Através de práticas pedagógicas que não se restrinjam aos conteúdos convencionais, mas sim em um processo educativo que tenha como pano de fundo o diálogo, as experiências, os interesses e as demandas de uma juventude plural. Assim, através do reconhecimento das particularidades juvenis - "gênero, raça, etnia, territorialidade, etapa de vida, orientação sexual, opção religiosa, características sensório-motoras, aspectos psicológicos, de classe social, etc." (CANDAU, 2012, p. 11), é possível desenvolver propostas que permitam e motivem a participação dos jovens na escola.

\section{Sexualidades na escola e o silenciamento das juventudes}

As considerações acima sobre o "protagonismo juvenil”, visibilizado segundo um norte adulto hegemônico, desmascaram a possibilidade de existência dos jovens enquanto sujeitos de sina sociedade. Refletindo sobre o que já foi exposto, pode-se inferir como a escola pode se constituir enquanto um espaço dialógico, que potencialize o protagonismo juvenil nas discussões sobre sexualidade? 
Quando a sexualidade se torna presente nas discussões escolares, ainda recebe conotação relacionada à área da saúde. Isto é, os diálogos entre professores e alunos se restringem aos cuidados médicos, sendo as discussões realizadas, majoritariamente, nas disciplinas de Ciências e Biologia (ALTMAN, 2005; BASTOS, G., 2015). Isso quando o assunto é abordado na escola, afinal, embora seja uma obrigatoriedade para todas as disciplinas, segundo os Parâmetros Curriculares Nacionais (BRASIL, 2000), as discussões sobre sexualidades podem ser vistas como incipientes pelos estudantes, que vivem a escola em seu cotidiano (ALTMAN, 2001). Tal superficialidade ao tratar do tema, pôde ser identificada na fala de uma das alunas participante da pesquisa, conforme exposto a seguir: "A pílula, se tiver tomando remédio controlado pode interferir, mas quase ninguém sabe disso! Porque não tem Educação Sexual na escola!” (Aluna 10). Desse modo, a aluna reafirma a ausência de discussões na escola sobre educação sexual, destacando, inclusive, a falta de aprofundamento em requisitos biológicos sobre o assunto. Ora, se existe esta demanda para um aprofundamento de caráter biológico no tema da educação sexual, quiçá sobre o estudo das sexualidades em formação dos jovens durante sua vida escolar e na sociedade.

A autora Campos (2017) fala sobre a necessidade de rompermos com as fronteiras da abordagem do assunto na escola, visto que a saúde sexual de nossos jovens se encontra em risco. Esse risco pode estar excedendo o campo biológico, com impactos na construção de suas próprias relações afetivas/sexuais, no quesito igualitário e satisfatório para ambos ou para si mesmos. Tal realidade, acaba limitando o desenvolvimento de uma sexualidade segura e prazerosa para os sujeitos envolvidos no processo.

É necessário que o ambiente escolar perceba e reconheça os jovens como sujeitos de direitos, em suas especificidades e subjetividades, sendo compreendidos para além dos estereótipos de "problemáticos sem causa". Assim, a juventude, como sujeitos de direitos, pode ter a oportunidade de exercitar as suas potencialidades e possibilidades na escola e sociedade em suas trajetórias de vida (DAYRELL, 2016).

Por isso, nesta pesquisa defendemos a escola como um lugar propício e potencial para momentos de diálogos e reflexões sobre sexualidades. Para Louro (2013) uma forma de lidar com o assunto no ambiente escolar, configura-se no movimento de respeito ao outro em suas necessidades e subjetividades. O autor Moura (2019) em seu estudo fala sobre a construção de uma sexualidade para além do campo biológico:

As sexualidades podem representar-se como sinônimo de experimentação sexual. Nesse contexto, esta experimentação sexual não deve apoiar-se apenas no ato sexual em si, mas em um movimento independente do corpo do outro, caracterizado como uma forma de busca e expressão dos sentimentos, desejos e prazer próprio sobre si mesmo ou até vivenciado com o outro, em uma movimentação constante, fluida e mutável pelas vivências de cada um na sociedade e refletido como um 'espelho' pelas suas especificidades. (p. 72).

Uma juventude que possui a possibilidade de pensar, repensar e refletir sua própria construção de sexualidade acaba exercendo também o direito de existir na sociedade e ressignificar essa existência segundo seus anseios, especificidades e próprio tempo. A escola permite essa realidade ou corrobora a manutenção dos discursos biológicos hegemônicos e generalistas em relação ao tema da sexualidade nesse lugar.

O desenvolvimento de uma juventude plural na sociedade que usufrua suas vidas para além dos padrões impostos pelos grupos sociais hegemônicos, depende que essas discussões sejam ocorridas em todos os espaços frequentados por esses jovens, inclusive no âmbito escolar.

Assim, faz se necessário na atualidade, um movimento na escola que possibilite a visibilidade das subjetividades dos principais atores participantes desse processo: nossos jovens estudantes e seu protagonismo no exercício de sua sexualidade. 


\section{Resultados/Discussão}

Durante as oficinas pedagógicas, os estudantes foram questionados em relação ao papel da escola, enquanto espaço para o desenvolvimento de reflexões sobre sexualidades. No fim das atividades, os participantes da pesquisa apontaram como se sentiram ao longo das oficinas pedagógicas, conforme pode ser verificado no Quadro 1 e puderam sugerir algumas abordagens possíveis, que a escola poderia utilizar para tratar sobre o tema educação e sexualidades, expressas no Quadro 2.

\section{Quadro 1 - Oficinas pedagógicas: percepções sobre a discussão do tema sexualidades na escola}

\begin{tabular}{|c|}
\hline $\begin{array}{c}\text { Percepções das oficinas } \\
\text { pedagógicas }\end{array}$ \\
\hline Compreensão \\
\hline Compreensão \\
\hline Leveza \\
\hline Aprendizagem \\
\hline Eu me senti normal \\
\hline Eu me senti normal \\
\hline Leveza \\
\hline Legal \\
\hline Compreendida \\
\hline Compreensão \\
\hline Aprendizagem \\
\hline Compreensão \\
\hline Justiça \\
\hline
\end{tabular}

Fonte: Elaborado pelos autores.

Em relação às percepções dos estudantes durante as oficinas pedagógicas, a maioria, demonstrou se sentir compreendido ao longo da experiência, seguido do sentimento de leveza, aprendizagem e justiça. Embora a escola seja vista como um espaço reconhecido pelo diálogo, a predominância da palavra "compreensão" entre as percepções dos estudantes, pode ser um reflexo da ausência de trocas nesse lugar quanto ao tema da sexualidade. Ou uma vez abordado, não seja compatível com os anseios desse público-alvo mediante suas necessidades. 
Quadro 2 - Percepções das oficinas pedagógicas: sugestões dos alunos para abordagem na escola

\begin{tabular}{|c|}
\hline $\begin{array}{c}\text { Sugestões dos alunos de como a } \\
\text { escola deveria abordar o tema }\end{array}$ \\
\hline Debate \\
\hline Com mais aulas \\
\hline Tendo aulas de psicologia e palestras para os alunos \\
independente da idade
\end{tabular}

Fonte: Elaborado pelos autores.

Quanto às sugestões indicadas pelos estudantes para que o tema da educação sexual e sexualidades seja tratado na escola, as palavras recorrentes em suas falas revelaram a urgência de espaços, que favoreçam o debate e o aprofundamento no cotidiano escolar. Um dos pontos destacados pelos alunos para que isso não ocorra na prática, encontra-se na figura do professor, que não aborda a temática em suas aulas.

Uma escola que se encontra aberta para se colocar no lugar do outro, assim como seu corpo docente, pode visibilizar a existência-vivência de todos os estudantes. Inclusive aqueles que apresentam uma orientação sexual e identidade de gênero consideradas diferentes em relação aos padrões hegemônicos presentes em nossa sociedade: homem-cis-heterossexual-branco-rico. Esse fato apareceu nas vivências relatadas a seguir:

A maioria das pessoas vão fazer sexo, portanto, acho que cabe a família orientar ou fazer sexo seguro respeitando a diversidade por exemplo: sexo lésbico. Ninguém fala como se proteger. A maioria das pessoas não sabe que sexo entre mulheres precisa sim de proteção, como preservativo feminino (pouquíssimo conhecido), o plástico filme. (Aluna 4).

Gravidez na adolescência deve se falar mais nas escolas, porque mesmo não precisando dessa ajuda, pode ajudar muitas meninas a tomar cuidado. E outra coisa que eu também acho que se deve falar em escola é sobre orientação sexual, gênero. Isso ajuda agente do Grupo LGBT até mesmo a elas, pra eles não crescer com isso na cabeça que é errado ou pra eles não se tornarem um monstro que é um(a) homofóbico(a). (Aluno 21).

$\mathrm{Na}$ fala desses estudantes se nota a presença de referenciais próprios acerca da orientação sexual e diversidade. Inferimos que o conhecimento relatado se encontra atrelado a um movimento gerado pelos próprios alunos para além da presença da escola em suas vidas. Heilborn (2004) nos 
apresenta considerações sobre a vivência da sexualidade em sujeitos que vivenciam uma orientação sexual diferente dos padrões determinados como normais em nosso tempo: um movimento que ocorre voltado para uma experimentação "mais consciente, vigilante e reflexiva" de si mesmo, visto os recorrentes casos de "violência, discriminação e estigmas" lançados sobre suas vidas.

A escola nos deixa marcas que muitas vezes nem o tempo "dá conta" de sanar devido a determinadas experiências opressoras vividas neste espaço. Desse modo, alguns estudantes do passado acabam retornando a esse ambiente como forma de ressignificação de si mesmo nesse lugar:

Voltar para a escola significava um acerto de contas com o passado. Não estava tão vulnerável como estive na infância e adolescência. A bicha preta migrava dos cantos escuros da escola, do fundo da sala de aula para a mesa da professora. A bicha preta escapulia ao destino que parecia imutável e conquistava o direito à fala e podia interferir positivamente na vida de estudantes pretos(as) e bichas. A certeza de uma existência restrita às beiradas se desfaz. (OLIVEIRA, 2017, p. 156).

Assim, os momentos revelados nas oficinas pedagógicas sugerem que os jovens participantes deste estudo não encontram na escola do seu tempo, um local que possibilite o exercício de seu protagonismo enquanto sujeitos de direitos em relação ao tema da sexualidade. Segundo Andrade e Câmara (2015), uma escola que se abre para o diálogo na diferença aponta caminhos para uma vivência plural neste lugar. Portanto, o diálogo encontra-se como eixo norteador de uma educação intercultural voltada para valorização da pluralidade no "chão da escola". O que reafirma a importância desse estudo e a necessidade de ampliação do mesmo, de modo que o protagonismo juvenil seja garantido e o tema da sexualidade seja tratado de forma responsável e consciente pelas escolas. Embora, alguns avanços tenham ocorrido neste debate na escola (BASTOS, F., 2015) no que tange ao tema da sexualidade e legitimação da presença do outro neste lugar devemos estar atentos aos ventos reacionários do nosso tempo. Vide, a atual configuração da Base Nacional Comum Curricular (BRASIL, 2017), que apresenta os termos gênero e orientação sexual suprimidos em sua constituição. Afinal neste documento, o debate da educação sexual na escola se direciona para uma abordagem exclusiva à reprodução humana engessado na disciplina de ciências, preterindo dessa forma as demais licenciaturas no assunto e questões culturais inerentes ao tema.

\section{Considerações Finais}

Os estudos sobre sexualidades na escola e a negação do protagonismo juvenil neste espaço, demonstram a necessidade de um olhar atento ao que é oferecido pela escola hoje, especialmente no que tange ao público jovem. Frequentemente caracterizado como "etapa problemática" e um "vir-a-ser", o jovem vê o seu significado social esvaziado de sentido, sendo caracterizado por noções superficiais que não contemplam a sua diversidade e individualidades. Combinado a este contexto, o tema das sexualidades persiste em um lugar de tabu, associado às questões biológicas e higienizantes, que limitam a sua complexidade, especialmente na escola.

Percebe-se nos jovens participantes desta pesquisa uma tentativa de busca pela compreensão de suas sexualidades e para legitimação da abordagem do tema na escola, pois ainda é abordado de forma incipiente segundo suas necessidades. A escola, enquanto instituição formadora, é desafiada a ressignificar o seu papel social, tendo como foco principal de sua transformação uma educação que seja mais aberta ao reconhecimento das diferenças na perspectiva de uma democracia participativa. Compreende-se, aqui, uma educação que considera todos os sujeitos envolvidos no processo educativo - gestão, professores, estudantes, famílias - em seu sentido mais completo (corpo, mente, emoções, valores) e, portanto, pessoas que buscam em sua experiência, não apenas os conhecimentos previamente estabelecidos, mas o encontro consigo mesmos e com os outros. 
Diante do exposto, compreendemos a juventude como etapa particular da vida, que exerce o seu direito de existir na sociedade. A sexualidade é parte integral da nossa constituição enquanto sujeitos e por isso, não pode ser subtraída frente aos demais conteúdos curriculares da escola. A construção das múltiplas sexualidades das juventudes apresenta para a escola atual um panorama que resiste ao silenciamento frequentemente imposto a esses sujeitos e às suas particularidades. Faz-se necessário e urgente, que a escola favoreça o debate significativo e interdisciplinar sobre o tema. As reflexões desenvolvidas podem partir mais do campo das possibilidades e compreensão do que das certezas, através de um processo educativo flexível que considere a juventude como etapa única e, portanto, particular, presente, ativa, pensante e diversa na sociedade.

\section{Referências}

ALTMANN, Helena. Orientação sexual nos parâmetros curriculares nacionais. Revista Estudos Feministas, Florianópolis, v. 9, n. 2, p. 575-585, 2001.

ALTMANN, Helena. Verdades e pedagogias na educação sexual em uma escola. 2005. Tese (Doutorado em Educação) - Programa de Pós-Graduação em Educação, Pontifícia Universidade Católica do Rio de Janeiro, Rio de Janeiro, 2005.

ANDRADE, Marcelo; CÂMARA, Luiz. Diferenças silenciadas e diálogos possíveis: a pesquisa em educação como superação de silenciamentos. In: ANDRADE, Marcelo (org.). Diferenças silenciadas: pesquisas em educação, preconceito e discriminações. 1. ed. Rio de Janeiro: 7 Letras, 2015. p. 8-28.

BASTOS, Felipe. "A diretora sabe que você está trabalhando isso na sala de aula?” Diversidade sexual e ensino de ciências. 2015. Dissertação (Mestrado em Educação) - Programa de Pós-Graduação em Educação, Pontifícia Universidade Católica do Rio de Janeiro, Rio de Janeiro, 2015.

BASTOS, Giséli Duarte. Biologia no Ensino Médio: diferentes abordagens metodológicas para adequar o conhecimento ao cotidiano - Enfoque sobre a Gravidez na Adolescência. 2015. Dissertação (Mestrado em Educação em Ciências) Programa de Pós-Graduação Educação em Ciências, Universidade Federal de Santa Maria, Santa Maria, 2015.

BRASIL. Base Nacional Comum Curricular. Brasília, DF: MEC, 2017. Disponível em: http://basenacionalcomum.mec. gov.br/images/BNC C_20dez_site.pdf. Acesso em: 15 jul. 2020.

BRASIL. Secretaria de Educação Fundamental. Parâmetros Curriculares Nacionais. 2. ed. Rio de Janeiro: DP\&A, 2000.

BORTOLINI, Alexandre. Diversidade sexual e de gênero na escola: Educação, Cultura, Violência e Ética. 1. ed. Rio de Janeiro: Pró- Reitoria de Extensão/ UFRJ, 2008.

CAMPOS, Helena Maria. Diálogos com adolescentes sobre relações amorosas, cidadania sexual e democracia intima: proposições para uma Educação em Saúde Emancipatória. 2017. Tese (Doutorado em Saúde Coletiva) - Instituto René Rachou, Programa de Pós-Graduação em Saúde Coletiva, Fundação Oswaldo Cruz, Belo Horizonte; Programa de Pós-Graduação em Direitos Humanos nas Sociedades Contemporâneas, Universidade de Coimbra, Coimbra, 2017.

CANDAU, Vera Maria Ferrão. Direito à Educação, Diversidade e Educação em Direitos Humanos. Educação e Sociedade, Campinas, v. 33, n. 120, p. 715-726, jul./set. 2012

CÉSAR, Maria Rita de Assis. Lugar de Sexo é na Escola? Sexo, Sexualidade e Educação sexual. In: SECRETARIA DE ESTADO DA EDUCAÇÃO; SUPERINTENDÊNCIA DE EDUCAÇÃO; DEPARTAMENTO DE DIVERSIDADES; NÚCLEO DE GÊNERO E DIVERSIDADE SEXUAL. Sexualidade. Curitiba: SEED, 2009. p. 49-58.

DAYRELL, Juarez. O jovem como sujeito social. Revista Brasileira de Educação, Rio de Janeiro, n. 24, p. 40-52, dez. 2003. Disponível em: https://www.scielo.br/j/rbedu/a/zsHS7SvbPxKYmvcX9gwSDty/abstract/?lang=pt. Acesso em: 13 jan. 2020.

DAYRELL, Juarez. Por uma pedagogia das juventudes: experiências educativas do Observatório da Juventude da UFMG. Belo Horizonte: Mazza Edições, 2016.

HEILBORN, Maria Luiza. (org). O aprendizado da sexualidade: reprodução e trajetórias sociais de jovens brasileiros. Rio de Janeiro: Garamond e Fiocruz, 2006. 
HEILBORN, Maria Luiza. Dois é par: gênero e identidade sexual em contexto igualitário. Rio de Janeiro: Garamond, 2004.

KINDEL, Eunice Aita Isaia. A docência em Ciências Naturais: construindo um currículo para o aluno e para a vida. Erechim: Edelbra, 2012.

LOURO, Guacira Lopes (org). Corpo, gênero e sexualidade: um debate contemporâneo na educação. 9. ed. Petrópolis: Vozes, 2013.

MINAYO, Maria Cecília de Souza (org). Pesquisa social: teoria, método e criatividade. Petrópolis: Vozes, 2007.

MOURA, Thiago de Souza. Ressignificando a Gravidez na Adolescência na escola: como as percepções das alunas e dos alunos estão permeadas pelas relações de gênero? 2019 Dissertação (Mestrado em Educação) - Programa de Pós-Graduação em Educação, Pontifícia Universidade Católica do Rio de Janeiro, Rio de Janeiro, 2019.

OLIVEIRA, Megg Rayara Gomes de. O diabo em forma de gente: (r)existências de gays afeminados, viados e bichas pretas na educação. 2017. Tese (Doutorado em Educação) - Programa de Pós-Graduação em Educação, Universidade Federal do Paraná, Curitiba, 2017.

ROCHA, Luciana Lins. Teoria queer e a sala de aula de inglês na escola pública: performatividade, indexicalidade e estilização. 2013. Tese (Doutorado em Línguística Aplicada) - Programa Interdisciplinar de Pós-Graduação em Linguística Aplicada, Universidade Federal do Rio de Janeiro, Rio de Janeiro, 2013.

SOUZA, Regina Magalhães de. Protagonismo juvenil: o discurso da juventude sem voz. Revista Brasileira de Adolescência e Conflitualidade, São Paulo, v. 1, n. 1, p. 1-28, 2009.

Data de submissão: 30/01/2021

Data de aceite: 13/02/2021 
